\title{
Augmentation of arginase 1 expression by exposure to air pollution exacerbates the airways hyperresponsiveness in murine models of asthma
}

\author{
Michelle L North 1,2,3,4, Hajera Amatullah ${ }^{3,4,5}$, Nivedita Khanna ${ }^{2,3,4}$, Bruce Urch ${ }^{1,3}$, Hartmut Grasemann ${ }^{1,6}$, \\ Frances Silverman ${ }^{1,2,3,4,5}$, Jeremy A Scott ${ }^{1,2,3,4,5^{*}}$
}

\begin{abstract}
Background: Arginase overexpression contributes to airways hyperresponsiveness (AHR) in asthma. Arginase expression is further augmented in cigarette smoking asthmatics, suggesting that it may be upregulated by environmental pollution. Thus, we hypothesize that arginase contributes to the exacerbation of respiratory symptoms following exposure to air pollution, and that pharmacologic inhibition of arginase would abrogate the pollution-induced AHR.

Methods: To investigate the role of arginase in the air pollution-induced exacerbation of airways responsiveness, we employed two murine models of allergic airways inflammation. Mice were sensitized to ovalbumin (OVA) and challenged with nebulized PBS (OVA/PBS) or OVA (OVA/OVA) for three consecutive days (sub-acute model) or 12 weeks (chronic model), which exhibit inflammatory cell influx and remodeling/AHR, respectively. Twenty-four hours after the final challenge, mice were exposed to concentrated ambient fine particles plus ozone $\left(\mathrm{CAP}+\mathrm{O}_{3}\right)$, or HEPA-filtered air (FA), for 4 hours. After the $\mathrm{CAP}+\mathrm{O}_{3}$ exposures, mice underwent tracheal cannulation and were treated with an aerosolized arginase inhibitor (S-boronoethyl-L-cysteine; BEC) or vehicle, immediately before determination of respiratory function and methacholine-responsiveness using the flexiVent ${ }^{\circledR}$. Lungs were then collected for comparison of arginase activity, protein expression, and immunohistochemical localization.
\end{abstract}

Results: Compared to FA, arginase activity was significantly augmented in the lungs of $\mathrm{CAP}+\mathrm{O}_{3}$-exposed OVA/OVA mice in both the sub-acute and chronic models. Western blotting and immunohistochemical staining revealed that the increased activity was due to arginase 1 expression in the area surrounding the airways in both models.

Arginase inhibition significantly reduced the $\mathrm{CAP}+\mathrm{O}_{3}$-induced increase in AHR in both models.

Conclusions: This study demonstrates that arginase is upregulated following environmental exposures in murine models of asthma, and contributes to the pollution-induced exacerbation of airways responsiveness. Thus arginase may be a therapeutic target to protect susceptible populations against the adverse health effects of air pollution, such as fine particles and ozone, which are two of the major contributors to smog.

\section{Background}

Epidemiological studies have described a relationship between ambient levels of air pollution, and respiratory admissions to hospitals [1,2]. It has become increasingly imperative to determine the biological effects of urban air pollutants, as they pose a serious risk to public

\footnotetext{
* Correspondence: jeremy.scott@utoronto.ca

'Institute of Medical Science, Faculty of Medicine, University of Toronto, Toronto, ON, Canada

Full list of author information is available at the end of the article
}

health and continue to present an enormous and increasing health and economic burden [3,4]. Investigations of the health impact of air pollution using controlled human exposures have demonstrated acute cardiopulmonary effects in both healthy subjects and asthmatics [5-7]. Fine particulate matter, with an aerodynamic diameter of less than $2.5 \mu \mathrm{m}$, has been specifically associated with increased mortality, pulmonary inflammation and oxidative stress [8-10]. Ozone $\left(\mathrm{O}_{3}\right)$ exposure has also been associated with asthma-related

\section{Biomed Central}

(c) 2011 North et al; licensee BioMed Central Ltd. This is an Open Access article distributed under the terms of the Creative Commons Attribution License (http://creativecommons.org/licenses/by/2.0), which permits unrestricted use, distribution, and reproduction in any medium, provided the original work is properly cited. 
hospital visits [11]. Fine particulate matter and $\mathrm{O}_{3}$ typically occur together in urban settings [7]. Therefore, it is important to understand the combined effects of these criteria air pollutants on cardiopulmonary disease. In particular, the role of these pollutants in asthma exacerbations remains to be fully understood.

Studies of gene-environment interactions have focused on the role of oxidative stress-responsive genes and air pollution exposures in asthma [12,13]. However, the mechanism(s) linking exposure to air pollution and asthma exacerbation remains unclear. The metabolism of L-arginine plays an important homeostatic role in the airways, through synthesis of the bronchodilating molecule, nitric oxide (NO), from L-arginine, by the nitric oxide synthase (NOS) isozymes [14]. The arginase isozymes (arginases 1 and 2), convert L-arginine into L-ornithine and urea, and thus compete with the NOS isozymes for substrate [15]. We and others have shown that arginase expression is upregulated in human asthma [16-18] and that the arginase isozymes play a functional role in the airways hyperresponsiveness (AHR) in animal models of asthma, using ovalbumin (OVA) [16,17,19,20], Aspergillus fumigatus [17], trimellitic anhydride exposure [21], and more recently house dust mite [22]. We have previously demonstrated that the AHR in a chronic murine model of allergic airways inflammation to OVA is due to arginase 1 overexpression [16]. Furthermore, single nucleotide polymorphisms of arginase 1 have been specifically associated with responsiveness to bronchodilators, and L-arginine bioavailability can impact airflow in asthma [23,24].

The arginase pathway has not previously been examined as a potential mechanism underlying the air pollution-induced exacerbation of asthma symptoms. However, arginase has been shown to be further upregulated in smoking asthmatics who are regularly and voluntarily exposed to high levels of particulate matter [25]. Furthermore, there is evidence to support uncoupling of the endothelial NOS in the vasculature following exposure to diesel exhaust [26], and dysfunction of endothelial-dependent vasorelaxation following exposure to second-hand tobacco smoke [27], likely as a consequence of a reduction in the bioavailability of L-arginine or tetrahydrobiopterin for the NOS pathway. Thus, it is plausible that dysregulation of L-arginine metabolism as a consequence of air pollution-induced upregulation of pulmonary arginase could contribute to the exacerbation of respiratory symptoms in susceptible asthmatics. We tested the hypothesis that arginase expression is augmented in response to exposures to environmental air pollutants, using two independent murine models of allergic airways inflammation; sub-acute and chronic models that mimic the inflammatory response and airways remodeling/AHR, respectively [28-31]. We demonstrate further upregulation of arginase following exposure to air pollution and attenuation of the pollution-induced AHR following treatment with an arginase inhibitor in both murine models of allergic airways inflammation.

\section{Methods}

\section{Sub-acute and chronic models of allergic airways} inflammation

All protocols were approved by the University of Toronto Faculty Advisory Committee on Animal Services, and were conducted in accordance with the guidelines of the Canadian Council on Animal Care, ensuring that the animals were treated humanely. To investigate the role of arginase in the exacerbation of airways responsiveness induced by air pollution exposure, we utilized two murine models of allergic airways inflammation: the subacute (16-day) and chronic (12-week) OVA-sensitization and -challenge models, which represent short-term allergic inflammatory changes and remodeling/hyperresponsiveness of the airways, respectively [30,31]. In both models, female BALB/c mice (6-8 weeks of age; Charles River Laboratories, Saint-Constant, PQ) were sensitized to OVA $\left(25 \mu \mathrm{g}\right.$ i.p. in $0.2 \mathrm{ml} \mathrm{PBS}$ with $1 \mathrm{mg} \mathrm{Al}(\mathrm{OH})_{3}$; Sigma Aldrich, Mississauga ON) one week apart (days 0 and 7), as described previously [16]. In the sub-acute model, the sensitized mice were randomized into two inhalation challenge groups (nebulized 6\% OVA (OVA/ OVA) or PBS (OVA/PBS)) for 25 minutes/day from days 14-16 (Figure 1A). In the chronic model, OVAsensitized mice were challenged with nebulized $2.5 \%$ OVA, on two consecutive days followed by a 12-day rest period (i.e., 2-week intervals), for up to 12 weeks (Figure 1A). For both models, 24 hours after the final OVA or PBS challenge, mice were exposed to concentrated ambient particles plus ozone $\left(\mathrm{CAP}+\mathrm{O}_{3}\right)$ or HEPA-filtered lab air (FA), as described below, and depicted in Figure 1B.

\section{Air Pollution Exposures}

Combined exposures to CAP and $\mathrm{O}_{3}$ were employed in this study. For controlled exposures to concentrated ambient fine particulate matter, we used the Harvard Ambient Particle Concentrator [32], which is a high-flow (5000 L/min) three-stage virtual impactor system that is part of the Southern Ontario Centre for Atmospheric Aerosol Research at the Gage Occupational and Environmental Health Unit. In this system, ambient air is drawn in, and real-world particles with an aerodynamic diameter 0.1-2.5 $\mu \mathrm{m}$ are concentrated approximately 40-fold (range: $196-954 \mu \mathrm{g} / \mathrm{m}^{3}$ ). $\mathrm{O}_{3}$ was produced by an arc generator using medical-grade oxygen and was introduced into the transition plenum between the second and third stages of the concentrator. CAP and $\mathrm{O}_{3}$ levels 

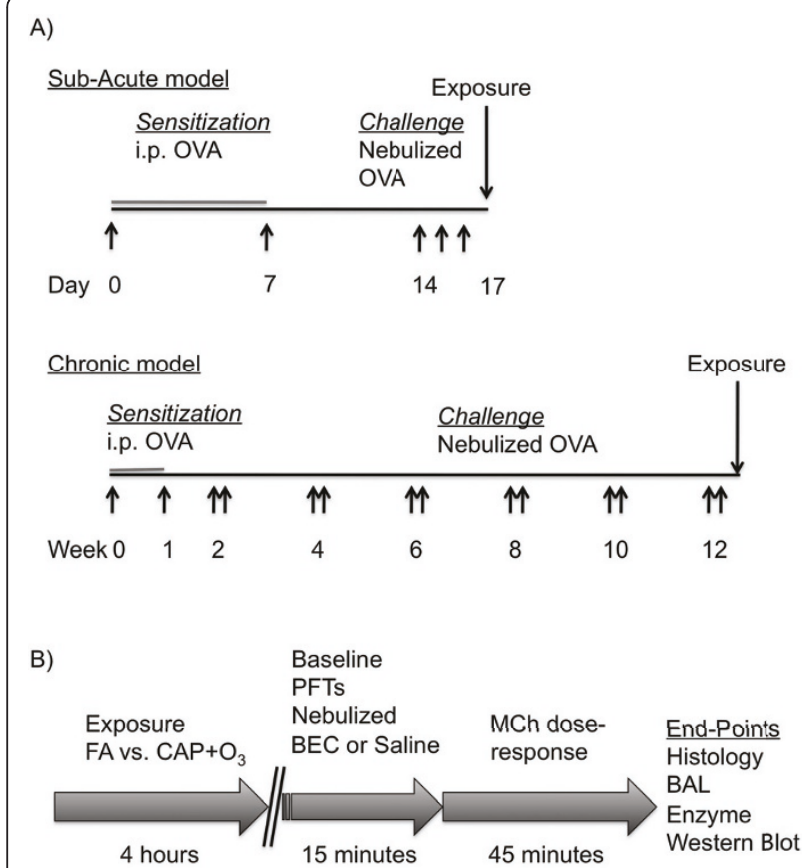

Figure 1 Experimental design and time-course. A) Schemas of the sensitization and challenge regimens of the sub-acute and chronic murine models of allergic airways inflammation. B) Experimental design and time-course of the pollution exposure day.

(>175 $\mu \mathrm{g} / \mathrm{m}^{3}$ and $2 \mathrm{ppm}$, respectively) were selected based upon previous inhalation exposure studies in rodents [33-35]. Mice were exposed to $\mathrm{CAP}+\mathrm{O}_{3}$ or FA for 4 hours at a flow rate of $2 \mathrm{~L} / \mathrm{min}$ (Figure 1B) using a modified inExpose nose-only inhalation system (Scireq Inc., Montréal, PQ) within a Plexiglas chamber. The $\mathrm{O}_{3}$ levels achieved using this system were monitored on the outflow from the chamber, using a Dasibi Model 1008RS ozone analyzer (Dasibi Environmental Corp, Glendale CA), and particle levels were determined gravimetrically (Table 1). In a subset of exposures, the constituents of the CAP were measured and the levels of major constituents (i.e., organic and elemental carbon, $\mathrm{NO}_{3}{ }^{-}, \mathrm{SO}_{4}{ }^{2-}$, and $\mathrm{NH}_{4}{ }^{+}$) were found to be consistent with our previous analyses of $\mathrm{PM}_{2.5}$ in Toronto [36] (data not shown). As our nose-only exposure system allows for the simultaneous exposure of 6 mice, CAP $+\mathrm{O}_{3}$ and FA exposures were conducted on 3 OVA/

Table 1 CAP and ozone exposure levels for the sub-acute and chronic models

\begin{tabular}{lll}
\hline & CAP $\left(\boldsymbol{\mu g} / \mathbf{m}^{\mathbf{3}}\right)^{\mathbf{a}}$ & Ozone (ppm) \\
\hline Sub-acute & $553 \pm 79$ & $1.80 \pm 0.07$ \\
\hline Chronic $^{\dagger}$ & $456 \pm 44$ & $1.79 \pm 0.04$ \\
\hline
\end{tabular}

${ }^{a}$ Values represent the mean \pm standard error of $n=8-11$ exposures.

+ There were no significant differences between the exposure levels for the sub-acute and chronic model mice.
OVA mice and 3 OVA/PBS controls at a time, to ensure comparable exposures between groups. Preliminary experiments indicated that the increase in methacholine responsiveness following exposure to $\mathrm{CAP}+\mathrm{O}_{3}$ was greater than that to either $\mathrm{CAP}$ or $\mathrm{O}_{3}$ alone (data not shown).

\section{Pulmonary Function Testing and Arginase Inhibition}

Following the $\mathrm{CAP}+\mathrm{O}_{3}$ or HEPA FA exposures, mice were anesthetized with ketamine $(50 \mathrm{mg} / \mathrm{kg}$ i.p., Bioniche, Belleville, ON)/xylazine (10 mg/kg i.p., Bayer Inc., Toronto, ON) for measurement of in vivo airways responsiveness to methacholine using the flexiVent ${ }^{\circledR}$ system (SciReq Inc., Montréal QC) [16]. The arginase inhibitor, $S$-boronoethyl L-cysteine (BEC; $40 \mu \mathrm{g} / \mathrm{g}$ body weight) or the PBS vehicle were nebulized directly into the airways after establishment of baseline resistance parameters, and allowed to equilibrate for 15 minutes prior to pulmonary function testing, in randomly selected mice from each model. We have previously found this dose to be effective in inhibiting arginase in acute and chronic murine models of asthma $[16,20]$. Respiratory mechanics were assessed using the linear first-order single compartment model, which provides resistance of the total respiratory system $(\mathrm{R})$, and the constant phase model, which utilizes forced oscillation to differentiate between airways resistance $\left(\mathrm{R}_{\mathrm{N}}\right)$ and peripheral tissue damping (G) $[30,37,38]$. Following pulmonary function testing, bronchoalveolar lavage (BAL) was performed in a subset of mice, for assessment of inflammation and 8-isoprostane as a marker of oxidative stress. All remaining lungs were harvested for protein analysis or immunohistochemical staining.

\section{Arginase activity and isozyme expression}

Total arginase activity testing and Western blotting for arginases 1 and 2 were performed as described previously [16]. Semi-quantitative assessment of the Western blots was conducted using a Bio-Rad Fluor-S Multilmager with the Bio-Rad Quantity One 4.3.0 software package (Bio-Rad Laboratories, Hercules, CA). Densitometry was performed using GelEval v1.22 (FrogDance Software, Dundee UK).

\section{Inflammation and Assessment of Immunohistochemical Localization of Arginase 1}

Differential cell counts were performed on cytospin slides (Shandon, Thermo Scientific, Waltham, MA), stained with DiffQuick (Dade Behring Inc., Newark, NJ). Differential cell counts were performed under a light microscope, by counting more than 300 cells per slide. Immunohistochemical staining of BAL cells and histological sections was performed using standard protocols at the Toronto Centre for Phenogenomics Pathology Core 
Facility, as previously described [16]. Goat anti-arginase 1 primary (sc-18351) and donkey anti-goat secondary (sc-2042) antibodies were purchased from Santa Cruz Biotechnologies (Santa Cruz, CA). For immunohistochemical counts of arginase 1-positive macrophages, macrophages were identified based on size and morphology using a hematoxylin counterstain. Lungs were collected for immunohistochemical staining and inflated to a pressure of $20 \mathrm{cmH}_{2} \mathrm{O}$ with $10 \%$ neutral buffered formalin (Sigma, Mississauga ON) [39]. For immunohistochemical analyses of tissue arginase 1 expression, slides were visualized on a Leica inverted microscope and images were captured using a micropublisher RTV 5.0 camera with QCapture image capture software (Quorum Technologies Inc., Guelph, ON).

\section{Oxidative Stress Marker}

As a marker of oxidative stress, 8-isoprostane levels (8-iso-prostaglandin $\mathrm{F}_{2 \alpha}$ ) were measured in BAL fluid using an enzyme immunoassay kit (8-Isoprostane EIA Kit. Item No. 516351, Cayman Chemical Company, Ann Arbor, MI), according to the manufacturer's instructions and standardized to protein concentration in the BAL, as determined by Bradford assay (BioRad, Hercules, CA).

\section{Statistics}

Statistical analyses were performed independently on the data from the sub-acute and chronic models. Specific respiratory measurements $\left(R, R_{N}, G\right)$, arginase activity and Western blotting densitometry data were analyzed using one-way ANOVA with Bonferroni's multiple comparison post-hoc test. BAL differential cell counts were analyzed using the non-parametric Kruskal-Wallis test with Dunn's Multiple Comparison post-hoc test, as some cell types were not observed in the OVA/PBS controls (i. e., eosinophils). Dose-response curves were compared using the F-test, with the null hypothesis that the data from all groups could be modelled by the same curve, and using two-way ANOVA with Bonferroni's post-hoc test. Correlations between exposure parameters and protein expression were determined by Spearman's test. P-values $<0.05$ were considered significant. All statistical analyses were performed using GraphPad Prism 4.0c.

\section{Results}

\section{Arginase activity and expression}

To investigate whether alterations in the arginase pathway were induced by exposure to air pollution we measured total arginase activity in mouse lung homogenates from $\mathrm{FA}$ and $\mathrm{CAP}+\mathrm{O}_{3}$ exposed mice. FA-exposed OVA/ OVA mice from both models exhibited significantly increased pulmonary arginase activity, relative to the FA-exposed OVA/PBS controls (Figure 2A \&2B). In both models, OVA/OVA mice exposed to $\mathrm{CAP}+\mathrm{O}_{3}$ exhibited further significant increases in pulmonary arginase activity, compared to the FA-exposed OVA/OVA mice (1.7- and 1.6-fold, respectively). $\mathrm{CAP}+\mathrm{O}_{3}$ exposure did not affect total pulmonary arginase activity in the OVA/PBS mice.

We used Western blotting to determine the contribution of the arginase isozymes to the increased total arginase activity. Arginase 1 expression was significantly increased in lungs from FA-exposed OVA/OVA mice in both models, relative to their respective OVA/PBS controls (Figure 2C \&2D). Following exposure to $\mathrm{CAP}+\mathrm{O}_{3}$, OVA/OVA mice in the sub-acute and chronic models exhibited further significant increases in pulmonary arginase 1 expression, relative to the FA exposed OVA/ OVA controls (2.6- and 1.7-fold, respectively). Interestingly, in the sub-acute model, the pulmonary expression of arginase 1 correlated directly with CAP exposure levels at concentrations lower than $565 \mu \mathrm{g} / \mathrm{m}^{3}$ (Spear$\operatorname{man} \rho=0.622, \mathrm{P}=0.013$; linear regression $\mathrm{r}^{2}=0.32$; $\mathrm{n}=15$ mice from 11 independent exposure days) (Figure 2E), suggesting that the CAP-induced increase in expression of arginase 1 was dose-dependent. At exposure levels above $565 \mu \mathrm{g} / \mathrm{m}^{3}$ we observed no further increase in arginase 1 expression, indicating a plateau in the response at higher levels. As the ozone exposures were fixed at the target concentration of $2 \mathrm{ppm}$, there was no correlation with protein expression. While pulmonary arginase 2 protein expression was increased significantly in the sub-acute model OVA/OVA mice under FA conditions, it was not further augmented by $\mathrm{CAP}+\mathrm{O}_{3}$ exposure. No significant increases in arginase 2 protein expression were observed in the chronic model mice, regardless of whether they were exposed to FA or $\mathrm{CAP}+\mathrm{O}_{3}$.

\section{Localization of increased arginase 1 expression}

To determine which cell types were responsible for the augmented arginase 1 expression following exposure to $\mathrm{CAP}+\mathrm{O}_{3}$, we investigated $\mathrm{BAL}$ and lung tissues, using immunohistochemical staining. We first examined the differential cell counts of the BAL samples from the sub-acute model. While there was an overall increase in the numbers of inflammatory cells in the OVA/OVA compared to OVA/PBS mice, there were no significant alterations in the differential cell counts in the $\mathrm{CAP}+\mathrm{O}_{3}$ compared with the FA exposure groups (Figure 3A).

As arginase 1 is known to be expressed in alternatively-activated macrophages [40], we investigated arginase 1 expression in BAL cells using immunohistochemistry. We did not observe any change in the proportion of arginase 1-positive macrophages in the immunostained BAL slides from the $\mathrm{CAP}+\mathrm{O}_{3}$-exposed OVA/PBS or OVA/OVA mice compared to their respective FA controls (Figure $3 \mathrm{~B}$ ). Thus, the increase in arginase 1 expression in the $\mathrm{CAP}+\mathrm{O}_{3}$-exposed mice was 


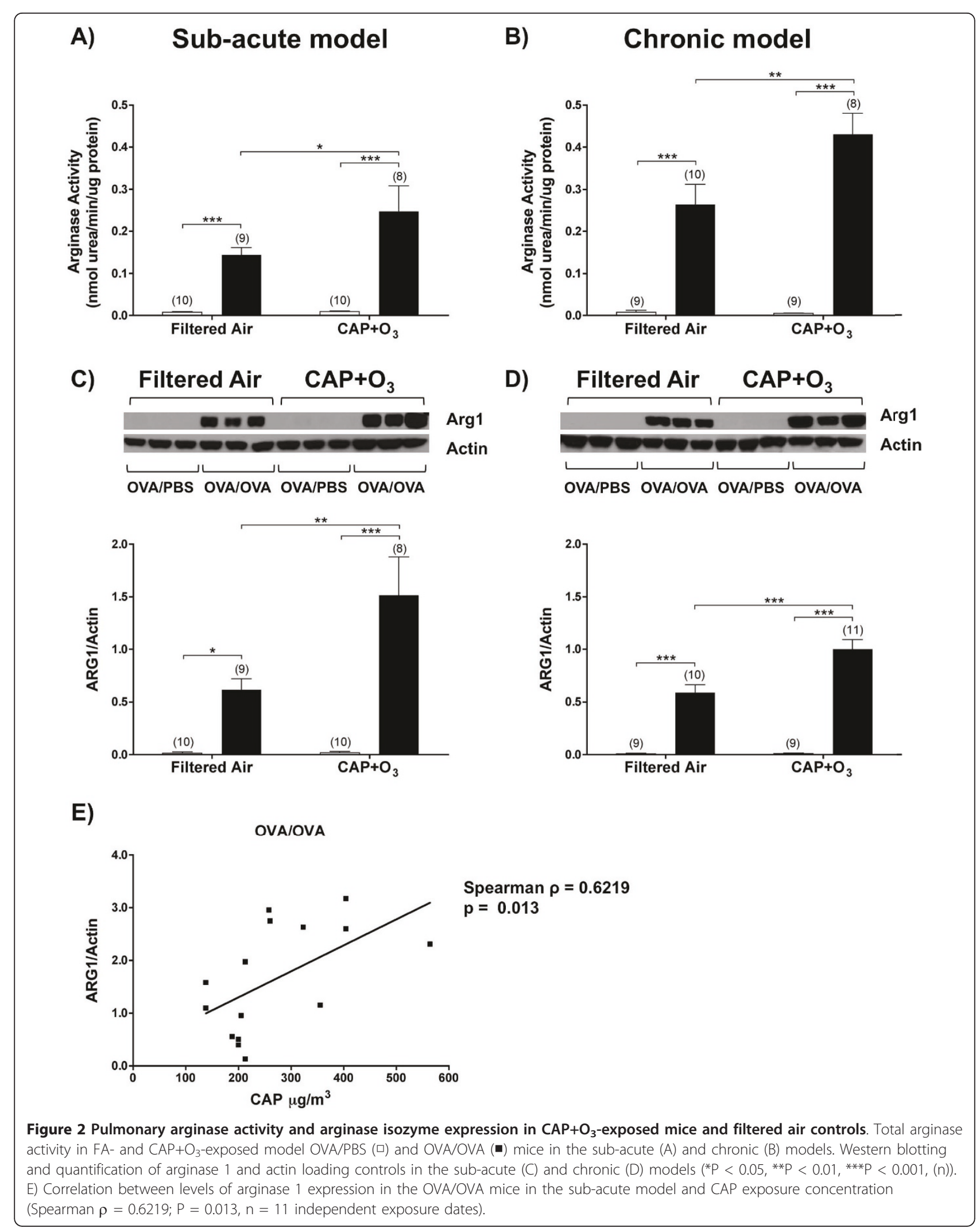




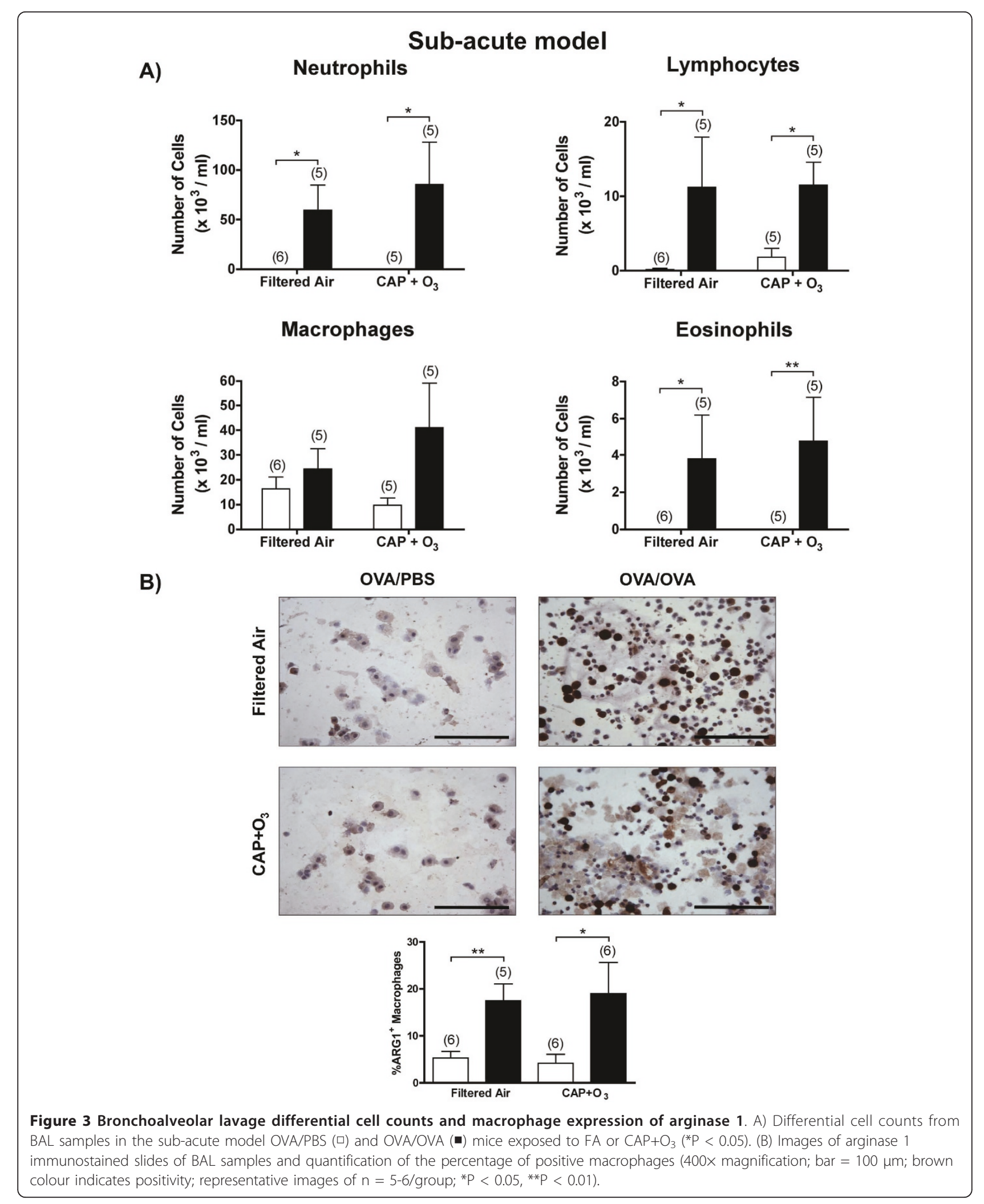


not due to an increased proportion of alternatively-activated macrophages infiltrating the lung.

We then investigated the expression of arginase 1 in airways in lung sections using immunohistochemical staining (Figure 4). Although expression was not quantifiable by these methods, staining was localized to the peribronchiolar region in both the sub-acute (Figure 4A) and chronic (Figure 4B) models.

\section{Effects of air pollution on methacholine responsiveness}

After demonstrating augmentation of arginase 1 protein expression in OVA/OVA mice exposed to $\mathrm{CAP}+\mathrm{O}_{3}$, we initially examined the functional effects of air pollution exposure on methacholine responsiveness in vivo in the sub-acute model. Total lung resistance (R) to methacholine was not significantly augmented in the OVA/OVA mice compared to OVA/PBS controls under FA conditions (Figure $5 \mathrm{~A}$ and $5 \mathrm{~B}$ ), making this model suitable to investigate the development of AHR induced specifically by $\mathrm{CAP}+\mathrm{O}_{3}$ exposure. Exposure to $\mathrm{CAP}+\mathrm{O}_{3}$ did not evoke any significant change in the methacholine responsiveness of the total lung in OVA/PBS mice (Figure 5A). However, significant augmentation of the methacholine dose-response curve was observed in the $\mathrm{CAP}+\mathrm{O}_{3}-$ exposed OVA/OVA mice, with a two-fold increase in the maximum resistance to methacholine, compared with the FA-exposed OVA/OVA controls (F-test and 2-way ANOVA, $\mathrm{P}<0.001$, Figure $5 \mathrm{~B}$ and $5 \mathrm{C}$ ). In the chronic model, FA-exposed OVA/OVA mice exhibited a moderate 1.5-fold increase in methacholine responsiveness compared with the OVA/PBS, FA-exposed controls $(\mathrm{P}=0.0418)$, which was further augmented by 1.6 -fold in $\mathrm{CAP}+\mathrm{O}_{3}$-exposed OVA/OVA mice $(\mathrm{P}=0.0071)$ (Figure 5D).

\section{Arginase inhibition abrogates the $\mathrm{CAP}+\mathrm{O}_{3}$-induced $\mathrm{AHR}$}

After determining that exposure to $\mathrm{CAP}+\mathrm{O}_{3}$ resulted in exacerbation of methacholine responsiveness in mice with pre-existing allergic airways inflammation, paralleling the up-regulation of pulmonary arginase 1 , we administered the arginase inhibitor, BEC, or vehicle control (PBS) to randomly selected sub-groups of mice following the $\mathrm{CAP}+\mathrm{O}_{3}$ exposures in both the sub-acute and chronic models. The maximum total respiratory resistance $\left(R_{\text {Max }}\right)$ was significantly increased in OVA/OVA mice vs. OVA/PBS from both models after the $\mathrm{CAP}+\mathrm{O}_{3}$ exposure (Figure $5 \mathrm{C}$ and $5 \mathrm{D}$ ). After treatment with $\mathrm{BEC}$, the $\mathrm{R}_{\mathrm{Max}}$ values in the $\mathrm{CAP}+\mathrm{O}_{3}$-exposed OVA/OVA mice was significantly attenuated compared with the PBS-treated controls (i.e., $\mathrm{CAP}+\mathrm{O}_{3}$-exposed OVA/OVA mice), and were indistinguishable from the $R_{\text {Max }}$ for the OVA/PBS controls. Thus, treatment with the arginase inhibitor completely reversed the $\mathrm{CAP}+\mathrm{O}_{3}$-induced exacerbation of symptoms in the OVA/OVA mice.
To confirm that the exacerbation of symptoms was due to effects on the airways, we assessed the contribution of airways resistance $\left(\mathrm{R}_{\mathrm{N} \text { Max }}\right)$ and peripheral tissue damping $\left(\mathrm{G}_{\mathrm{Max}}\right)$ to the total response of the lung. In the sub-acute model, $R_{N}$ Max was not altered significantly following $\mathrm{CAP}+\mathrm{O}_{3}$ exposure, or by $\mathrm{BEC}$ treatment (Figure 6A). Interestingly, $\mathrm{G}_{\mathrm{Max}}$ was increased significantly following exposure to $\mathrm{CAP}+\mathrm{O}_{3}$ in the sub-acute OVA/OVA mice, and was attenuated to control levels by arginase inhibition with BEC (Figure 6C). Meanwhile, in the chronic model OVA/OVA mice, $\mathrm{R}_{\mathrm{N} \text { Max }}$ was significantly augmented by $\mathrm{CAP}+\mathrm{O}_{3}$, and significantly reversed by treatment with BEC (Figure $6 \mathrm{~B})$. A significant increase in $\mathrm{G}_{\mathrm{Max}}$ was also observed in the chronic model OVA/OVA mice following $\mathrm{CAP}+\mathrm{O}_{3}$ exposure, however this was not attenuated by BEC treatment (Figure 6D). Exposure to $\mathrm{CAP}+\mathrm{O}_{3}$ or administration of BEC did not affect any of the responsiveness parameters in the OVA/PBS mice in either model (Figure 5 and 6).

\section{Oxidative Stress Due to $\mathrm{CAP}+\mathrm{O}_{3}$ Exposures}

To assess the level of oxidative stress induced by exposure to $\mathrm{CAP}+\mathrm{O}_{3}$, we determined levels of 8- prostaglandin $F_{2 \alpha}$ (8-isoprostane) in BAL supernatants from both the sub-acute and chronic models (Table 2). In the subacute model, the levels of 8 -isoprostane were $7.9 \pm 3.6$ and $9.7 \pm 4.1 \mathrm{pg} / \mathrm{mg}$ of BAL protein in the OVA/PBS and OVA/OVA FA groups, respectively $(\mathrm{P}=$ n.s. $)$. OVA/PBS and OVA/OVA mice exposed to CAP $+\mathrm{O}_{3}$ exhibited 5.4- and 7.0-fold increases compared to the FA groups $(\mathrm{P}<0.05$ to $\mathrm{FA})$. In the chronic model, BAL levels of 8-isoprostane in the OVA/OVA FA-exposed mice were 1.9-fold greater than those in the OVA/PBS FA-exposed mice $(\mathrm{P}=0.017)$. OVA/PBS and OVA/ OVA mice exposed to $\mathrm{CAP}+\mathrm{O}_{3}$ exhibited 3.5- and 2.3-fold increases in 8-isoprostane levels compared to their respective FA controls $(\mathrm{P}<0.05)$. There was no significant difference in BAL 8-isoprostane levels between the OVA/PBS and OVA/OVA $\mathrm{CAP}+\mathrm{O}_{3}$-exposed groups.

\section{Discussion}

This study demonstrated that the increased arginase activity in the lungs of mice from both sub-acute and chronic models of allergic airways inflammation was further augmented by exposure to $\mathrm{CAP}+\mathrm{O}_{3}$, and that this was primarily driven by arginase 1 . We also determined that the up-regulation of arginase 1 in the lung was not related to increased influx of macrophages. Finally, we demonstrated that induction of AHR by CAP $+\mathrm{O}_{3}$ was specific to the mice with pre-existing allergic airways inflammation, and that local delivery of an arginase inhibitor after exposure, significantly reduced the $\mathrm{CAP}+\mathrm{O}_{3}$-induced AHR in both models; thus providing 


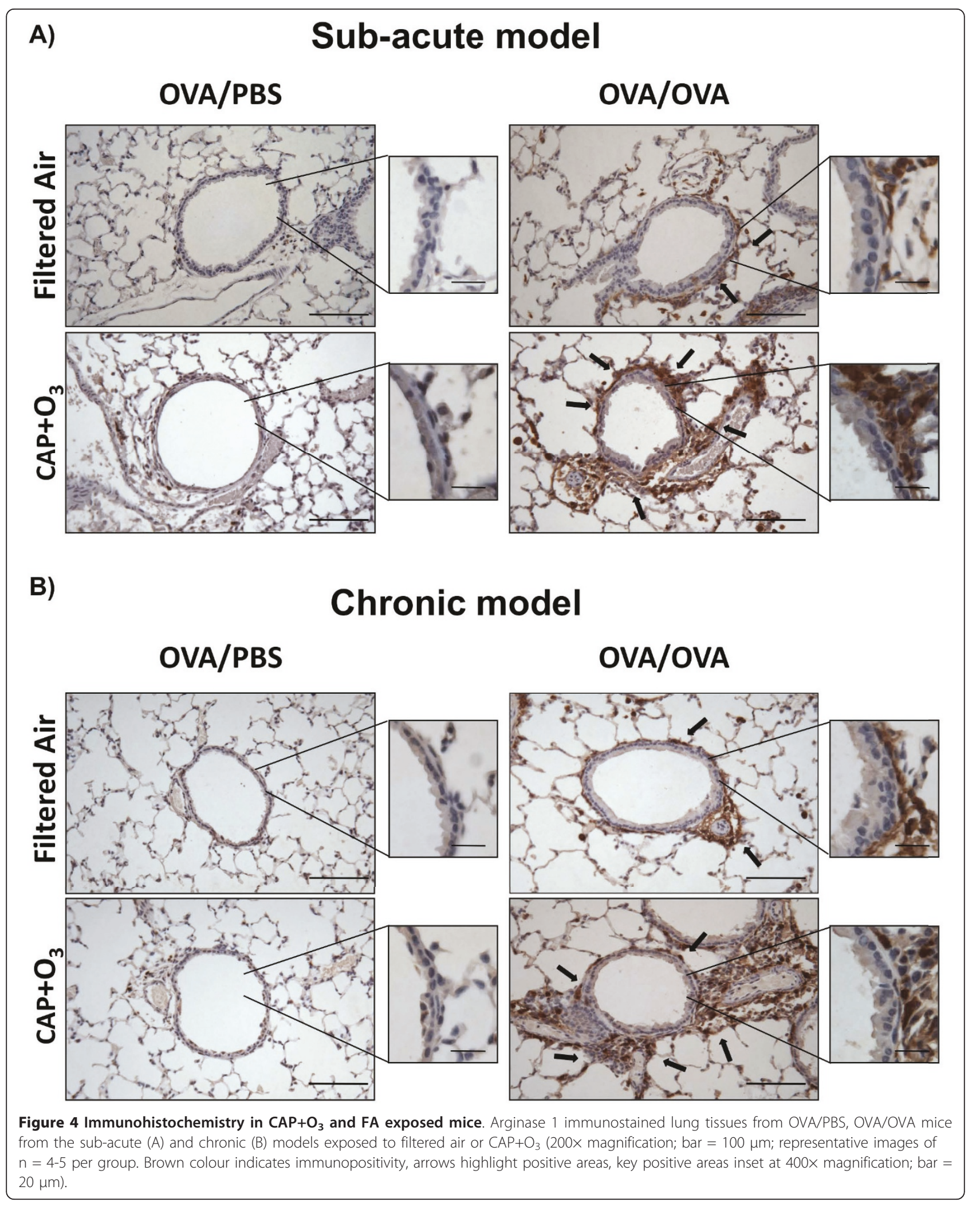




\section{Total lung resistance Sub-acute model}

A)

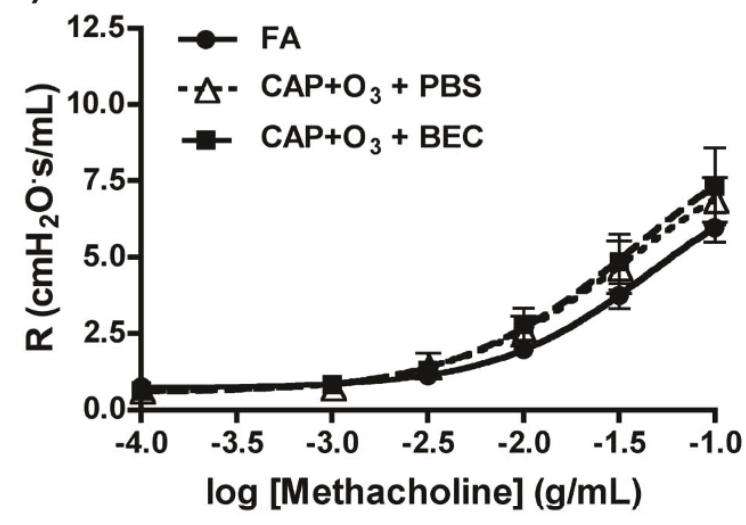

B)

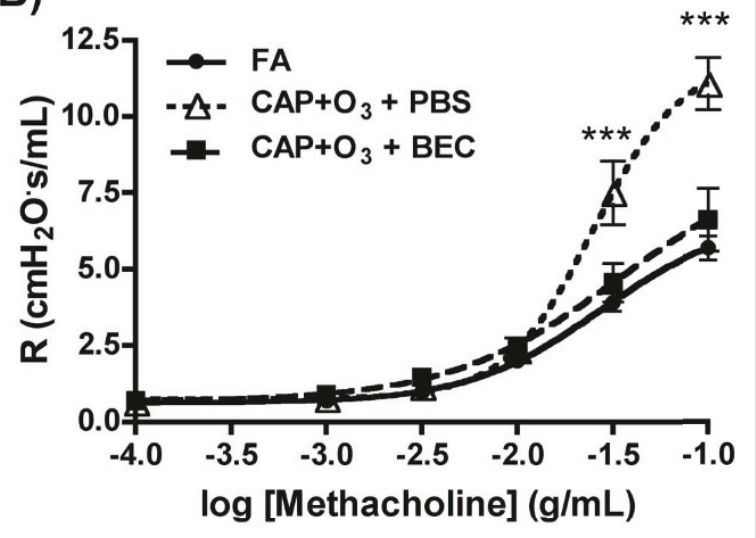

\section{Sub-acute}

C)

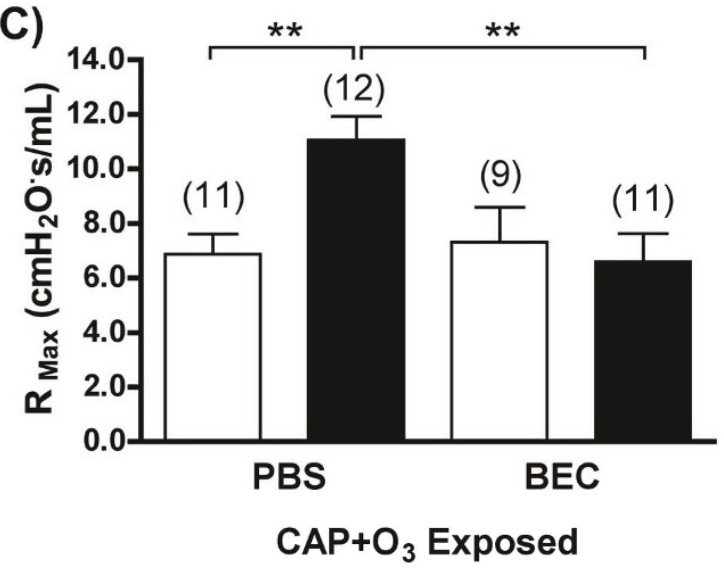

Chronic

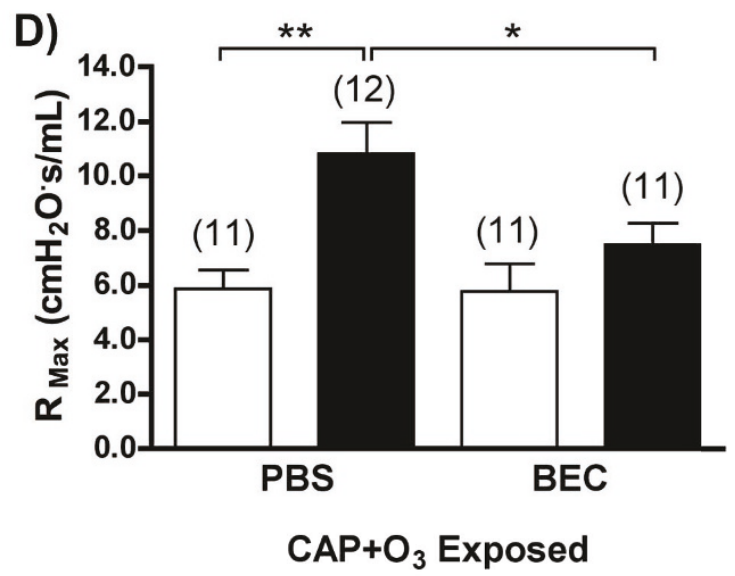

Figure 5 Functional effects of $\mathrm{CAP}+\mathrm{O}_{3}$ exposure on airways responsiveness to methacholine and attenuation by arginase inhibition. Dose-response relationships for the increase in total lung resistance (R) to methacholine in OVA/PBS (A) and OVA/OVA (B) mice from the subacute model exposed to $\mathrm{FA}$ or $\mathrm{CAP}+\mathrm{O}_{3}$. Effects of treatment with arginase inhibitor (BEC) vs. vehicle control (PBS) on maximum total lung resistance $\left(\mathrm{R}_{\text {Max }}\right)$ in OVA/PBS ( $\square$ ) and OVA/OVA (- $)$ mice following $C A P+\mathrm{O}_{3}$ exposures in the sub-acute (C) and chronic (D) models $\left({ }^{*} \mathrm{P}<0.05,{ }^{* *}\right.$ $P<0.01,{ }^{* * *} P<0.001 ; n=9-12$ /group).

further support for the potential of targeting this pathway therapeutically in asthma.

Arginase induction by $\mathrm{CAP}+\mathrm{O}_{3}$

There is increasing evidence to support the role of arginase in the pathophysiology of asthma, and that further up-regulation of arginase likely results in worsening of asthma symptoms [15-19]. The sub-acute model mice in the present study, challenged with ovalbumin daily for three days, exhibited significantly lower arginase 1 expression and airways responsiveness, compared to the acute OVA-model mice reported in our previous study, in which we employed seven consecutive daily challenges [16]. Thus, increased arginase 1 expression is directly associated with the increasing airways responsiveness in these murine models $(P=0.002$, Spearman 


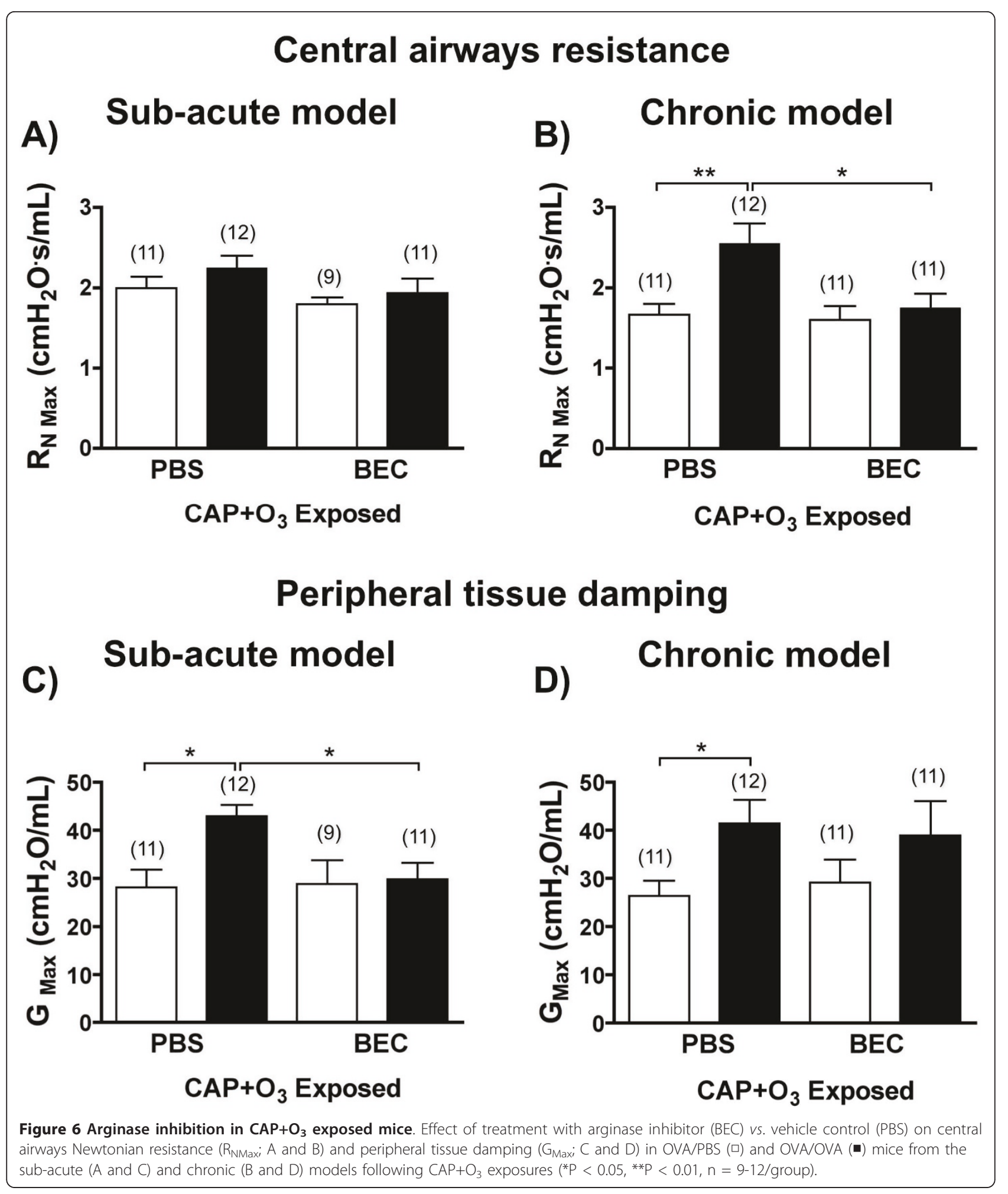

$\rho=0.522$ ). We speculate that there is a critical threshold of arginase induction, at which the increased arginase activity exhibits physiological effects. Air pollution is known to contribute to asthma exacerbations [41-43]. Increased levels of particulate matter and ozone have been associated with increased oxidative stress and decreased pulmonary function in children with asthma [44]. Increased arginase protein expression has been observed in smokers with asthma [25], but it is not known whether arginase plays a role in air pollution- 
Table 2 8-isoprostane levels in BAL samples from the sub-acute and chronic OVA-model mice exposed to filtered air or $\mathrm{CAP}+\mathrm{O}_{3}$

\begin{tabular}{lllll}
\hline & \multicolumn{2}{c}{ Filtered Air $^{\text {a }}$} & \multicolumn{2}{c}{${\mathrm{CAP}+\mathrm{O}_{3}}$} \\
\cline { 2 - 5 } & OVA/PBS & OVA/OVA & OVA/PBS & OVA/OVA \\
\hline Sub-acute & $7.9 \pm 3.6$ & $9.7 \pm 4.1$ & $42.5 \pm 11.4^{\#}$ & $67.4 \pm 22.4^{\#}$ \\
\hline Chronic & $19.0 \pm 3.3$ & $36.8 \pm 5.0^{*}$ & $65.7 \pm 16.0^{\#}$ & $83.0 \pm 17.0^{\#}$ \\
\hline
\end{tabular}

${ }^{a}$ Values are expressed as pg 8-isoprostane/mg BAL protein and represent the mean \pm standard error of $n=5-6$ samples.

${ }^{*} \mathrm{P}<0.05$ to OVA/PBS, same exposure; ${ }^{\#} \mathrm{P}<0.05$ to Filtered air, same treatment.

induced exacerbations of respiratory symptoms. In this study we demonstrated further augmentation of arginase activity and arginase 1 expression in the airways of our OVA-sensitized and -challenged mice following exposure to $\mathrm{CAP}+\mathrm{O}_{3}$.

Arginase 1 protein expression in blood serum has recently been associated with markers of oxidative stress in a healthy human population [45], and augmented arginase activity correlates with indices of oxidative stress (i. e., malondialdehyde and protein carbonylation levels) in platelets and plasma from patients with chronic obstructive pulmonary disease exposed to wood smoke [46]. Arginase 1 has also been reported to be induced in isolated coronary arterioles following one hour of ex vivo exposure to hydrogen peroxide-induced oxidative stress [47]. Thengchaisri et al. also demonstrated changes in smooth muscle function in response to increased oxidative stress, and demonstrated that arginase inhibition restored the hydrogen peroxide-impaired vasodilation [47]. However, in our model we only observed an increase in arginase 1 in mice that were previously sensitized and challenged with ovalbumin; while, we observed increases in 8-isoprostane levels in the BAL samples from all mice exposed to $\mathrm{CAP}+\mathrm{O}_{3}$ regardless of the presence or absence of airways inflammation. This may be due to differences in experimental procedures, as Thengchaisri et al. exposed isolated coronary arterioles to hydrogen peroxide ex vivo [47], while we examined the whole lung following in vivo acute $\mathrm{CAP}+\mathrm{O}_{3}$ exposure. Alternatively, toll-like receptors, the hallmark regulators of the innate immune response to bacterial, viral, and parasitic components, have recently been shown to upregulate arginase 1 via an alternative promoter region [48]. It is highly likely that some of these biologic exposures are relevant to our CAP exposures. Further work is necessary to elucidate the mechanisms underlying the upregulation of arginase 1 in response to environmental stimuli in the presence of an inflammatory response.

While we did not investigate the effects of long-term pollution exposure in these models, our findings raise the interesting question of whether continued exposures would result in chronic upregulation of arginase, and lead to remodeling of the airways. Increased airway wall remodeling has been observed by Dai et al., following exposure of rat tracheal explants to Ottawa urban air particles [49]. Diesel exhaust particles can also potentiate airways remodeling in a house dust mite murine model of allergic airways inflammation [50] that is known to exhibit augmented arginase expression [22]. Thus, arginase may be induced as part of the host response to cell damage by air pollution, as it is known to be involved in cell growth and wound healing [51]. As the metabolic pathways downstream of arginase are related to cellular proliferation and collagen biosynthesis, it is likely that augmented arginase expression contributes to airways remodeling in asthma [52]. The role of L-arginine metabolism in the effects of chronic air pollution exposure, and the effects of concomitant inhibition of arginase represent future avenues for investigation.

\section{Functional improvement of airways hyperresponsiveness with arginase inhibition}

Although the arginase pathway has been shown to be functionally involved in the development of AHR in vivo following allergen challenges with ovalbumin $[16,19,20,53]$ and house dust mite [22], it was not clear whether this pathway would be functionally important in the exacerbation of AHR induced by air pollution. In this investigation we used two mouse models of asthma, which exhibit the inflammatory changes, remodeling and moderate AHR as symptoms of allergic airways disease; while the OVA/OVA mice in the sub-acute model did not exhibit AHR to methacholine, those in the chronic model did exhibit moderate AHR, which was consistent with our previous report [16]. We further demonstrated exacerbation of the AHR in the chronic model and the development of AHR in the sub-acute model after exposure to air pollution. In both murine models we demonstrated an increase in the maximum total lung resistance following air pollution exposure, and that inhibition of arginase, post-exposure, blocked this effect. We also examined the contribution of the airways and peripheral tissue to the net response. Using a sub-acute model of allergic airways inflammation, Tomioka et al. previously demonstrated that the effects of allergic inflammation in this model were more pronounced in the lung periphery and thus affected peripheral lung mechanics more strongly than conducting airways mechanics [38]. However, it was not known how the added challenge of a $\mathrm{CAP}+\mathrm{O}_{3}$ exposure would affect peripheral lung mechanics in the sub-acute model. Our data suggest that $\mathrm{CAP}+\mathrm{O}_{3}$ exposure specifically aggravated peripheral lung responsiveness to methacholine in the OVA/OVA mice in this sub-acute model. Arginase inhibition with BEC completely 
abrogated the augmented $G_{\text {Max }}$, strongly suggesting a role for arginase in the functional exacerbation of peripheral AHR by air pollution in the sub-acute model.

The particles we employed were derived from the ambient air in Toronto, Ontario, and particles within a specific size range $(0.1-2.5 \mu \mathrm{m})$ were concentrated, representing real-world particles. We examined the effects of concentrated ambient particles and ozone, as these pollutants have been shown to be associated with increased asthma exacerbations in humans, and because concomitant exposures have been shown to increase respiratory resistance in mice, thus allowing our study to examine the biological mechanisms responsible for these effects $[1,2,11,54]$. Murine models present several limitations, as no animal model exhibits all of the clinical features of human asthma [30,55-57]. However, our sub-acute model exhibits airways inflammation and our chronic model recapitulates airways remodeling and mild hyperresponsiveness, all of which are important features of human asthma [28,58], and mice in both models exhibited an even greater degree of airways hyperresponsiveness following air pollution exposures. Asthmatics as a group represent a potential susceptible population that would be more significantly affected by air pollution than those who do not have underlying respiratory disease. Our results support this idea, as we did not observe increased airways responsiveness in the control mice, but demonstrated an increase in mice with pre-existing allergic airways inflammation.

While the doses of particulate matter and ozone employed in this study are high, similar doses have been shown to be useful for studying acute mechanisms of air pollution induced AHR in the setting of allergic airways inflammation and healthy controls [33-35]. Exposure to high levels of ozone can induce pulmonary edema and lung injury [35,59]. While OVA/PBS control mice that were exposed concurrent with the OVA/OVA mice in our study did not exhibit any alterations in inflammatory cell counts or profiles in bronchoalveolar lavage samples obtained immediately after $\mathrm{CAP}+\mathrm{O}_{3}$ exposures, the possibility remains that our findings could be due solely to the high-level exposures. Interestingly, the OVA/PBS mice exposed to $\mathrm{CAP}+\mathrm{O}_{3}$ exhibited a slight increase in methacholine responsiveness compared with FA. Similarly, the OVA/OVA mice exposed to $\mathrm{CAP}+\mathrm{O}_{3}$ that were treated with $\mathrm{BEC}$ exhibited a similar increase of methacholine responsiveness, suggesting that pathways unrelated to arginase induction, such as edema, could contribute to this non-significant increase. Thus, further investigations will be necessary to determine whether the pathways activated by acute high-level exposures are similar to those activated after chronic exposures to lower levels of particulate matter and ozone.
The chronic model offers the ability to study exacerbation of established disease, in a model that recapitulates more of the features of chronic human asthma, including remodeling, collagen deposition, smooth muscle hypertrophy, and mild AHR [16,28,60-62]. Furthermore, we have previously shown that the chronic model exhibits alterations in the profile of L-arginine-related protein expression that are most similar to those of human asthma [16]. In the chronic model OVA/OVA mice, we found that both central airways resistance and peripheral tissue damping contributed to the pulmonary response to $\mathrm{CAP}+\mathrm{O}_{3}$ exposure. However only central airways resistance was attenuated by $\mathrm{BEC}$, suggesting that arginase-independent effects, such as lung edema or the accumulation of endogenous NOS inhibitors (i.e., ADMA) [63,64], may also be induced by exposure to air pollution and contribute to AHR. While we observed a correlation between CAP exposures and arginase induction in OVA-sensitized and -challenged mice, future studies should assess the dose-effects of air pollutants and corroborate the findings with additional model allergens.

\section{Conclusions}

Arginase activity and arginase 1 expression are upregulated following environmental exposures in both subacute and chronic murine models of allergic asthma. Pollution-induced AHR is attenuated by arginase inhibition in both models. Thus, induction of arginase 1 is likely a key step in the short-term response to air pollution and inhibition may represent a therapeutic target to treat or prevent environmental pollution-induced exacerbations of allergic airways disease.

\section{Abbreviations \\ AHR: airways hyperresponsiveness; BAL: bronchoalveolar lavage; BEC: S- boronoethyl-L- cysteine; CAP: concentrated ambient particles; $E_{50}$ : half- maximal effective concentration; FA: filtered air; G: peripheral tissue damping; NOS: nitric oxide synthase; $\mathrm{O}_{3}$ : Ozone; OVA: ovalbumin; PBS: phosphate buffered saline; $R$ : total resistance of the respiratory system; $R_{N}$ : resistance of the central airways.}

\section{Acknowledgements}

The authors thank Dr. Mingyao Liu for thoughtful comments on the manuscript. The authors thank Mike Fila and Mary Speck for assistance with exposures, and input on the design of the exposure system, respectively. The authors thank Dr. Jeffrey R. Brook, Ministry of Environment, for the constituent analysis and helpful comments. This study was supported by the AllerGen NCE, the National Sanitarium Association, and the Keenan Research Centre of the Li Ka Shing Knowledge Institute of St. Michael's Hospital. MN is a recipient of a CIHR Doctoral Award.

\section{Author details}

${ }^{1}$ Institute of Medical Science, Faculty of Medicine, University of Toronto, Toronto, ON, Canada. ${ }^{2}$ Divisions of Occupational and Respiratory Medicine, Department and Faculty of Medicine, University of Toronto, Toronto, ON, Canada. ${ }^{3}$ Gage Occupational and Environmental Health Unit, University of Toronto and St. Michael's Hospital, Toronto, ON, Canada. ${ }^{4}$ Keenan Research Centre in the Li Ka Shing Knowledge Institute of St. Michael's Hospital, 
Toronto, ON, Canada. ${ }^{5}$ Division of Occupational and Environmental Health, Dalla Lana School of Public Health, Faculty of Medicine, University of Toronto, Toronto, ON, Canada. ${ }^{6}$ Program in Physiology and Experimental Medicine, Research Institute, and Division of Respiratory Medicine, Department of Paediatrics, The Hospital for Sick Children, University of Toronto, Toronto, ON, Canada.

\section{Authors' contributions}

MN carried out the murine studies, molecular biology, immunohistochemical, pulmonary function analyses and drafted the manuscript. HA conducted the analyses of macrophage arginase 1 expression. NK participated in pulmonary function testing and performed the differential cell counts. BU participated in the design of the exposure system and co-ordination of the air pollution exposures. HG participated in the conception and design of the study and critical revision of the manuscript for important intellectual content. FS participated in the conception and design of the study and critical revision of the manuscript for important intellectual content. JS participated in the conception and design of the study, pulmonary function and statistical analyses, drafting of the manuscript and critical revision for important intellectual content. All authors read and approved the final manuscript.

\section{Competing interests}

The authors declare that they have no competing interests.

Received: 20 August 2010 Accepted: 3 February 2011

Published: 3 February 2011

\section{References}

1. Chang J, Delfino RJ, Gillen D, Tjoa T, Nickerson B, Cooper D: Repeated respiratory hospital encounters among children with asthma and residential proximity to traffic. Occup Environ Med 2009, 66:90-98.

2. Burnett RT, Dales RE, Raizenne ME, Krewski D, Summers PW, Roberts GR, Raad-Young M, Dann T, Brook J: Effects of low ambient levels of ozone and sulfates on the frequency of respiratory admissions to Ontario hospitals. Environ Res 1994, 65:172-194.

3. Hall JV, Brajer, Victor, Lurmann, Frederick W: The Benefits of Meeting Federal Clean Air Standards in the South Coast and San Joaquin Valley Air Basins. Institute for Economic and Environmental Studies 2008, Institute Report.

4. Canadian Medical Association C: No Breathing Room: National Illness Costs of Air Pollution. NICAP Summary Report 2008.

5. Urch B, Silverman F, Corey P, Brook JR, Lukic KZ, Rajagopalan S, Brook RD: Acute blood pressure responses in healthy adults during controlled air pollution exposures. Environ Health Perspect 2005, 113:1052-1055.

6. Gong H, Linn WS, Sioutas C, Terrell SL, Clark KW, Anderson KR, Terrell LL: Controlled exposures of healthy and asthmatic volunteers to concentrated ambient fine particles in Los Angeles. Inhal Toxicol 2003, 15:305-325.

7. Brook RD, Urch B, Dvonch JT, Bard RL, Speck M, Keeler G, Morishita M, Marsik FJ, Kamal AS, Kaciroti N, et al: Insights into the mechanisms and mediators of the effects of air pollution exposure on blood pressure and vascular function in healthy humans. Hypertension 2009, 54:659-667.

8. Zanobetti A, Schwartz J: The effect of fine and coarse particulate air pollution on mortality: a national analysis. Environ Health Perspect 2009, 117:898-903.

9. Klemm RJ, Mason RM, Heilig CM, Neas LM, Dockery DW: Is daily mortality associated specifically with fine particles? Data reconstruction and replication of analyses. J Air Waste Manag Assoc 2000, 50:1215-1222.

10. Tao F, Gonzalez-Flecha B, Kobzik L: Reactive oxygen species in pulmonary inflammation by ambient particulates. Free Radic Biol Med 2003, 35:327-340.

11. Lin S, Liu X, Le LH, Hwang SA: Chronic exposure to ambient ozone and asthma hospital admissions among children. Environ Health Perspect 2008, 116:1725-1730.

12. London SJ: Gene-air pollution interactions in asthma. Proc Am Thorac Soc 2007, 4:217-220.

13. Castro-Giner F, Kunzli N, Jacquemin B, Forsberg B, de Cid R, Sunyer J, Jarvis $D$, Briggs $D$, Vienneau $D$, Norback $D$, et al: Traffic-related air pollution, oxidative stress genes, and asthma (ECHRS). Environ Health Perspect 2009, 117:1919-1924.
14. Ricciardolo FL, Sterk PJ, Gaston B, Folkerts G: Nitric oxide in health and disease of the respiratory system. Physiol Rev 2004, 84:731-765.

15. Maarsingh $\mathrm{H}$, Zaagsma J, Meurs $\mathrm{H}$ : Arginine homeostasis in allergic asthma. Eur J Pharmacol 2008, 585:375-384.

16. North ML, Khanna N, Marsden PA, Grasemann H, Scott JA: Functionally important role for arginase 1 in the airway hyperresponsiveness of asthma. Am J Physiol Lung Cell Mol Physiol 2009, 296:L911-920.

17. Zimmermann N, King NE, Laporte J, Yang M, Mishra A, Pope SM, Muntel EE, Witte DP, Pegg AA, Foster PS, et al: Dissection of experimental asthma with DNA microarray analysis identifies arginase in asthma pathogenesis. J Clin Invest 2003, 111:1863-1874.

18. Morris CR, Poljakovic M, Lavrisha L, Machado L, Kuypers FA, Morris SM Jr: Decreased arginine bioavailability and increased serum arginase activity in asthma. Am J Respir Crit Care Med 2004, 170:148-153.

19. Maarsingh $H$, Zuidhof $A B$, Bos IS, van Duin M, Boucher JL, Zaagsma J, Meurs H: Arginase inhibition protects against allergen-induced airway obstruction, hyperresponsiveness, and inflammation. Am J Respir Crit Care Med 2008, 178:565-573.

20. North ML, Meurs H, Zaagsma J, Scott JA, Maarsingh H: Arginase in Asthma - Recent Developments in Animal and Human Studies. The Open Nitric Oxide Journal 2010, 2:20-36.

21. Greene AL, Rutherford MS, Regal RR, Flickinger GH, Hendrickson JA, Giulivi C, Mohrman ME, Fraser DG, Regal JF: Arginase activity differs with allergen in the effector phase of ovalbumin- versus trimellitic anhydrideinduced asthma. Toxicol Sci 2005, 88:420-433.

22. Takahashi N, Ogino K, Takemoto K, Hamanishi S, Wang DH, Takigawa T, Shibamori $\mathrm{M}$, Ishiyama $\mathrm{H}$, Fujikura Y: Direct inhibition of arginase attenuated airway allergic reactions and inflammation in a Dermatophagoides farinae-induced NC/Nga mouse model. Am J Physiol Lung Cell Mol Physiol 2010, 299:L17-24.

23. Litonjua AA, Lasky-Su J, Schneiter K, Tantisira KG, Lazarus R, Klanderman B, Lima JJ, Irvin CG, Peters SP, Hanrahan JP, et al: ARG1 is a novel bronchodilator response gene: screening and replication in four asthma cohorts. Am J Respir Crit Care Med 2008, 178:688-694.

24. Lara A, Khatri SB, Wang Z, Comhair SA, Xu W, Dweik RA, Bodine M, Levison BS, Hammel J, Bleecker E, et al: Alterations of the arginine metabolome in asthma. Am J Respir Crit Care Med 2008, 178:673-681.

25. Bergeron C, Boulet LP, Page N, Laviolette M, Zimmermann N, Rothenberg ME, Hamid Q: Influence of cigarette smoke on the arginine pathway in asthmatic airways: increased expression of arginase I. J Allergy Clin Immunol 2007, 119:391-397.

26. Knuckles TL, Lund AK, Lucas SN, Campen MJ: Diesel exhaust exposure enhances venoconstriction via uncoupling of eNOS. Toxicol Appl Pharmacol 2008, 230:346-351.

27. Hutchison SJ, Sievers RE, Zhu BQ, Sun YP, Stewart DJ, Parmley WW, Chatterjee K: Secondhand tobacco smoke impairs rabbit pulmonary artery endothelium-dependent relaxation. Chest 2001, 120:2004-2012.

28. Allen JE, Bischof RJ, Sucie Chang HY, Hirota JA, Hirst SJ, Inman MD, Mitzner W, Sutherland TE: Animal models of airway inflammation and airway smooth muscle remodelling in asthma. Pulm Pharmacol Ther 2009, 22:455-465.

29. Leigh R, Ellis R, Wattie JN, Hirota JA, Matthaei Kl, Foster PS, O'Byrne PM, Inman MD: Type 2 cytokines in the pathogenesis of sustained airway dysfunction and airway remodeling in mice. Am J Respir Crit Care Med 2004, 169:860-867.

30. Bates JH, Rincon M, Irvin CG: Animal models of asthma. Am J Physiol Lung Cell Mol Physiol 2009, 297:L401-410.

31. Kelly MM, Leigh R, Bonniaud P, Ellis R, Wattie J, Smith MJ, Martin G, Panju M, Inman MD, Gauldie J: Epithelial expression of profibrotic mediators in a model of allergen-induced airway remodeling. Am J Respir Cell Mol Biol 2005, 32:99-107.

32. Sioutas $C$, Koutrakis P, Burton RM: A technique to expose animals to concentrated fine ambient aerosols. Environ Health Perspect 1995, 103:172-177.

33. Kierstein S, Krytska K, Sharma S, Amrani Y, Salmon M, Panettieri RA, Zangrilli J, Haczku A: Ozone inhalation induces exacerbation of eosinophilic airway inflammation and hyperresponsiveness in allergensensitized mice. Allergy 2008, 63:438-446.

34. Harkema JR, Wagner JG, Kaminski NE, Morishita M, Keeler GJ, McDonald JD, Barrett EG: Effects of concentrated ambient particles and diesel engine 
exhaust on allergic airway disease in Brown Norway rats. Res Rep Health Eff Inst 2009, 5-55.

35. Garantziotis S, Li Z, Potts EN, Lindsey JY, Stober VP, Polosukhin W, Blackwell TS, Schwartz DA, Foster WM, Hollingsworth JW: TLR4 is necessary for hyaluronan-mediated airway hyperresponsiveness after ozone inhalation. Am J Respir Crit Care Med 2010, 181:666-675.

36. Urch B, Brook JR, Wasserstein D, Brook RD, Rajagopalan S, Corey P, Silverman F: Relative contributions of PM2.5 chemical constituents to acute arterial vasoconstriction in humans. Inhal Toxicol 2004, 16:345-352.

37. Hantos Z, Daroczy B, Suki B, Nagy S, Fredberg JJ: Input impedance and peripheral inhomogeneity of dog lungs. J Appl Physiol 1992, 72:168-178.

38. Tomioka S, Bates JH, Irvin CG: Airway and tissue mechanics in a murine model of asthma: alveolar capsule vs. forced oscillations. J Appl Physiol 2002, 93:263-270.

39. Hsia CC, Hyde DM, Ochs M, Weibel ER: An official research policy statement of the American Thoracic Society/European Respiratory Society: standards for quantitative assessment of lung structure. Am J Respir Crit Care Med 2010, 181:394-418.

40. Gordon S: Alternative activation of macrophages. Nat Rev Immunol 2003, 3:23-35

41. Kim H, Bernstein JA: Air pollution and allergic disease. Curr Allergy Asthma Rep 2009, 9:128-133.

42. Patel MM, Miller RL: Air pollution and childhood asthma: recent advances and future directions. Curr Opin Pediatr 2009, 21:235-242.

43. Riedl MA: The effect of air pollution on asthma and allergy. Curr Allergy Asthma Rep 2008, 8:139-146.

44. Liu L, Poon R, Chen L, Frescura AM, Montuschi P, Ciabattoni G, Wheeler A, Dales R: Acute effects of air pollution on pulmonary function, airway inflammation, and oxidative stress in asthmatic children. Environ Health Perspect 2009, 117:668-674.

45. Ogino K, Takahashi N, Takigawa T, Obase Y, Wang DH: Association of serum arginase I with oxidative stress in a healthy population. Free Radic Res 2011, 45:147-155.

46. Guzman-Grenfell A, Nieto-Velazquez N, Torres-Ramos Y, Montoya-Estrada A, Ramirez-Venegas A, Ochoa-Cautino L, Flores-Trujillo F, Hicks JJ: Increased platelet and erythrocyte arginase activity in chronic obstructive pulmonary disease associated with tobacco or wood smoke exposure. J Investig Med 2011.

47. Thengchaisri N, Hein TW, Wang W, Xu X, Li Z, Fossum TW, Kuo L: Upregulation of arginase by $\mathrm{H} 2 \mathrm{O} 2$ impairs endothelium-dependent nitric oxide-mediated dilation of coronary arterioles. Arterioscler Thromb Vasc Biol 2006, 26:2035-2042.

48. El Kasmi KC, Qualls JE, Pesce JT, Smith AM, Thompson RW, HenaoTamayo M, Basaraba RJ, Konig T, Schleicher U, Koo MS, et al: Toll-like receptor-induced arginase 1 in macrophages thwarts effective immunity against intracellular pathogens. Nat Immunol 2008, 9:1399-1406.

49. Dai J, Xie C, Vincent R, Churg A: Air pollution particles produce airway wall remodeling in rat tracheal explants. Am J Respir Cell Mol Biol 2003, 29:352-358.

50. Takahashi G, Tanaka H, Wakahara K, Nasu R, Hashimoto M, Miyoshi K, Takano H, Yamashita H, Inagaki N, Nagai H: Effect of diesel exhaust particles on house dust mite-induced airway eosinophilic inflammation and remodeling in mice. J Pharmacol Sci 2010, 112:192-202.

51. Wu G, Bazer FW, Davis TA, Kim SW, Li P, Marc Rhoads J, Carey Satterfield M, Smith $S B$, Spencer TE, Yin Y: Arginine metabolism and nutrition in growth, health and disease. Amino Acids 2009, 37:153-168.

52. Maarsingh $H$, Pera T, Meurs H: Arginase and pulmonary diseases. Naunyn Schmiedebergs Arch Pharmacol 2008, 378:171-184.

53. Bratt JM, Franzi LM, Linderholm AL, O'Roark EM, Kenyon NJ, Last JA: Arginase inhibition in airways from normal and nitric oxide synthase 2-knockout mice exposed to ovalbumin. Toxicol Appl Pharmacol 2010, 242:1-8.

54. Farraj AK, Boykin E, Ledbetter A, Andrews D, Gavett SH: Increased lung resistance after diesel particulate and ozone co-exposure not associated with enhanced lung inflammation in allergic mice. Inhal Toxicol 2010, 22:33-41.

55. Maes T, Provoost S, Lanckacker EA, Cataldo DD, Vanoirbeek JA, Nemery B, Tournoy KG, Joos GF: Mouse models to unravel the role of inhaled pollutants on allergic sensitization and airway inflammation. Respir Res 2010, 11:7.
56. Wenzel S, Holgate ST: The mouse trap: It still yields few answers in asthma. Am J Respir Crit Care Med 2006, 174:1173-1176, discussion 11761178.

57. Shapiro SD: Animal models of asthma: Pro: Allergic avoidance of animal (model[s]) is not an option. Am J Respir Crit Care Med 2006, 174:1171-1173.

58. O'Byrne PM, Inman MD: Airway hyperresponsiveness. Chest 2003, 123:411S-416S

59. Uysal N, Schapira RM: Effects of ozone on lung function and lung diseases. Curr Opin Pulm Med 2003, 9:144-150.

60. Ellis R, Leigh R, Southam D, O'Byrne PM, Inman MD: Morphometric analysis of mouse airways after chronic allergen challenge. Lab Invest 2003, 83:1285-1291.

61. Hirota JA, Ellis R, Inman MD: Regional differences in the pattern of airway remodeling following chronic allergen exposure in mice. Respir Res 2006, 7:120.

62. Kenyon NJ, Last JA: Reversible and irreversible airway inflammation and fibrosis in mice exposed to inhaled ovalbumin. Inflamm Res 2005, 54:57-65.

63. Klein E, Weigel J, Buford MC, Holian A, Wells SM: Asymmetric dimethylarginine potentiates lung inflammation in a mouse model of allergic asthma. Am J Physiol Lung Cell Mol Physiol 2010, 299:L816-825.

64. Ahmad T, Mabalirajan U, Ghosh B, Agrawal A: Altered asymmetric dimethyl arginine metabolism in allergically inflamed mouse lungs. Am J Respir Cell Mol Biol 2010, 42:3-8.

doi:10.1186/1465-9921-12-19

Cite this article as: North et al:: Augmentation of arginase 1 expression by exposure to air pollution exacerbates the airways hyperresponsiveness in murine models of asthma. Respiratory Research 2011 12:19

\section{Submit your next manuscript to BioMed Central and take full advantage of:}

- Convenient online submission

- Thorough peer review

- No space constraints or color figure charges

- Immediate publication on acceptance

- Inclusion in PubMed, CAS, Scopus and Google Scholar

- Research which is freely available for redistribution

Submit your manuscript at www.biomedcentral.com/submit
Ciomed Central 